\title{
Impact of hydrogen onboard storage technologies on the performance of hydrogen fuelled vehicles: A techno-economic well-to-wheel assessment
}

\author{
Marc P. de Wit*, André P.C. Faaij \\ Department of Science, Technology and Society, Copernicus Institute for Sustainable Development and Innovation, \\ Utrecht University, Heidelberglaan 2, 3584 CS Utrecht, The Netherlands
}

Received 26 January 2007; received in revised form 6 July 2007; accepted 6 July 2007

Available online 7 September 2007

\begin{abstract}
Hydrogen onboard storage technologies form an important factor in the overall performance of hydrogen fuelled transportation, both energetically and economically. Particularly, advanced storage options such as metal hydrides and carbon nanotubes are often hinted favourable to conventional, liquid and pressurized, storage options. This study assesses the technical and economic performance of four onboard storage technologies in a well-to-wheel assessment. It does so for centralized and onsite hydrogen production scenarios with gaseous pipeline and liquid truck distributed hydrogen. Energetically, centralized production and liquefaction outperforms onsite production and liquefaction by $20 \%$ on the average primary energy input, despite the need of pipeline or over the road distribution. The gaseous handling on the filling station performs better with an average driving energy use of $0.11 \mathrm{MJ}_{\mathrm{p}} / \mathrm{km}$ compared to $0.15 \mathrm{MJ} / \mathrm{km}$ for liquid handling. The advanced onboard storage technologies perform better by $22 \%$ than the conventional storage technologies on primary energy input in the chain. The average driving cost for gaseous and liquid onboard storage are 53\% above the gasoline reference cost of $21 € \mathrm{ct} / \mathrm{km}$ and the advanced onboard storage technologies as much as $98 \%$, almost double the reference cost. The car expenditure for a fuel cell driven car compared to an internal combustion engine driven car is for a large part responsible for this difference. Advanced onboard storage technologies thus perform better than conventional onboard storage technologies energetically albeit to higher cost.
\end{abstract}

(C) 2007 International Association for Hydrogen Energy. Published by Elsevier Ltd. All rights reserved.

Keywords: Hydrogen onboard storage technology; Metal hydrides; Carbon nanotubes; Liquid storage; Pressurized storage; Well-to-wheel assessment

\section{Introduction}

With hydrogen becoming a possible contender to replace conventional car fuels, hydrogen production, conversion and storage technologies are subject to intensive research and development $(\mathrm{R} \& \mathrm{D})$. Hydrogen is considered a promising energy carrier for a number of reasons. The diverse feedstocks hydrogen can be derived from give flexibility in the choice of primary energy resources with respect to availability and price. This flexibility is also an essential characteristic in the complex transition process in which a gradual shift from conventional (fossil) feedstocks towards sustainable feedstocks for hydrogen production is foreseen [1]. In an early stage of transition,

\footnotetext{
* Corresponding author. Tel.: +31302537610; fax: +31302537600 .

E-mail address: m.p.dewit@uu.nl (M.P. de Wit).
}

dominated by a large share of fossil resources, carbon dioxide sequestration and storage can ensure a gradual shift to sustainable transport.

One of the major barriers for large scale use of hydrogen is the infrastructural changes needed in the transition towards a hydrogen based transportation sector. The handling of gaseous hydrogen requires a radically different design on almost all levels of the supply chain infrastructure, including; production, distribution, refuelling and the vehicle design itself. Advanced storage technologies are currently and will in the future be heavier and require more space in the vehicle than conventional storage technologies. This may limit flexibility to the vehicle design and negatively affects the fuel economy. Costs related to this radical change and to the economic competitive production of hydrogen sustainably, pose another problem. The increase in overall chain efficiency that is foreseen, presumes that a mature, proton exchange membrane (PEM), fuel cell 


\begin{tabular}{|llll|}
\hline \multicolumn{2}{l}{ Nomenclature } & $\mathrm{LH}_{2}$ & liquid hydrogen \\
$\mathrm{CNT}$ & carbon nanotube & $\mathrm{MH}$ & metal hydrides \\
$\mathrm{CPSC}$ & compressed steel cylinder & $\mathrm{PEM}$ & proton exchange membrane \\
FCV & fuel cell vehicles & PSA & pressure swing adsorption \\
$\mathrm{HFV}$ & hydrogen fuelled vehicle & R\&D & research and development \\
$\mathrm{ICE}(\mathrm{V})$ & internal combustion engine (vehicle) & SMR & steam methane reforming \\
\hline
\end{tabular}

technology for vehicles is available. PEM fuel cell technologies are, however, not expected to become commercially available for vehicle applications until 2020 [2]. Other factors, not directly related to energy or cost performance, affecting the overall performance of a storage technology are a longer refuelling time and possible poor material durability, influencing, apart from cost, the reliability of the product.

The supply chain and filling station handling of hydrogen differs from conventional fuel handling in the way that hydrogen is gaseous, with a low energy density, even at very low temperatures. The gaseous state of the hydrogen requires compression steps in the different stages of the hydrogen supply chain. The pressure gradient in the total chain is a decisive aspect in the overall chain efficiency. Current hydrogen onboard storage technologies store hydrogen in compressed or liquid form. The limited energy density of these storage technologies presents barriers with respect to required tank volumes and energy requirements for refuelling. These can influence vehicle costs and thus well-to-wheel costs significantly. In the search for storage options featuring more favourable characteristics, new advanced options are being researched.

Several advanced storage technologies are under research. Current studies underline the breakthrough role that advanced storage technologies can play, if cost and energetic performance goals are met [13]. The current results of fundamental laboratory studies, however, do not yet approach the possible theoretical performance predicted and required to fulfil the claims of favourable characteristics made by the industry [6]. Because of the fundamental stage of the R\&D (e.g. [3-6]), the concrete future impact potential on the well-to-wheel performance of hydrogen fuelled vehicles (HFVs) is unclear.

Chain analysis is a much used approach in the evaluation of the impact of a specific aspect on the fuel supply chain. Aspects often considered in a well-to-wheel analysis are; energy efficiency, overall costs and the environmental impact. With respect to hydrogen supply chains, numerous system studies have been executed, with different subjects of focus. In several studies (e.g. [7-9]) different modes of onboard hydrogen use are evaluated, hydrogen refuelling with compressed hydrogen storage onboard and also studies that consider fossil fuel refuelling and onboard conversion into hydrogen by means of onboard steam reforming and onboard partial oxidation of hydrogen. Others [8] study hydrogen chains and focus on the evaluation of different applications for distribution, e.g. pipeline, liquid truck and rail. Analyses with respect to storage cost at different stages of the supply chain - production plant, filling station and onboard storage - are rather limited and not analysed in a chain approach $[9,10]$.

The objective of this paper is to evaluate the potential future techno-economic performance of onboard storage technologies by means of a chain analysis. The analysis consists of two parts: (1) a review is made of the status of the hydrogen storage options, their performance and improvement potential. (2) The storage options are compared for different supply chains, including hydrogen production at different scales and pressures. For doing so, the energetic performances of 14 pathways are analysed, resulting in an outcome of primary energy per kilometre driven, per technology. In addition a similar approach is applied to evaluate the economic performance, resulting in the calculated costs in euro per kilometre driven, per technology. The environmental impact of the chains is focussed on the calculated energy performance and on greenhouse gas emissions (an indication for one aspect of the environmental impact). Results can help identify pathways for efficient and (more) competitive use of hydrogen for road transport in general, and the impact of advanced hydrogen storage technologies in particular.

\section{Method}

The onboard storage media require hydrogen in liquid or gaseous form under different pressures, depending on specifications of the onboard storage technology. The supply chains and filling station configurations are designed in such a way to facilitate these requirements. The analysis is executed using a well-to-wheel approach. The results are given in terms of primary energy ${ }^{1}$ use per kilometre driven and related cost. First the chains are defined. In the chain configuration some aspects and parameters are distinguished, which are discussed below. Three different filling station configurations are presented.

\subsection{Chain definition}

Firstly, the production of hydrogen, central and decentral (onsite) steam methane reforming (SMR) and liquifaction, is analysed based on literature data. This is relevant to enable analysis with respect to scale, efficiency and cost.

Secondly, the distribution system, gaseous pipeline distribution, liquid truck transport and filling station configurations are

\footnotetext{
1 Primary energy: Energy embodied in natural resources (e.g. coal, crude oil, sunlight, uranium) that has not undergone any anthropogenic conversions or transformations [11].
} 


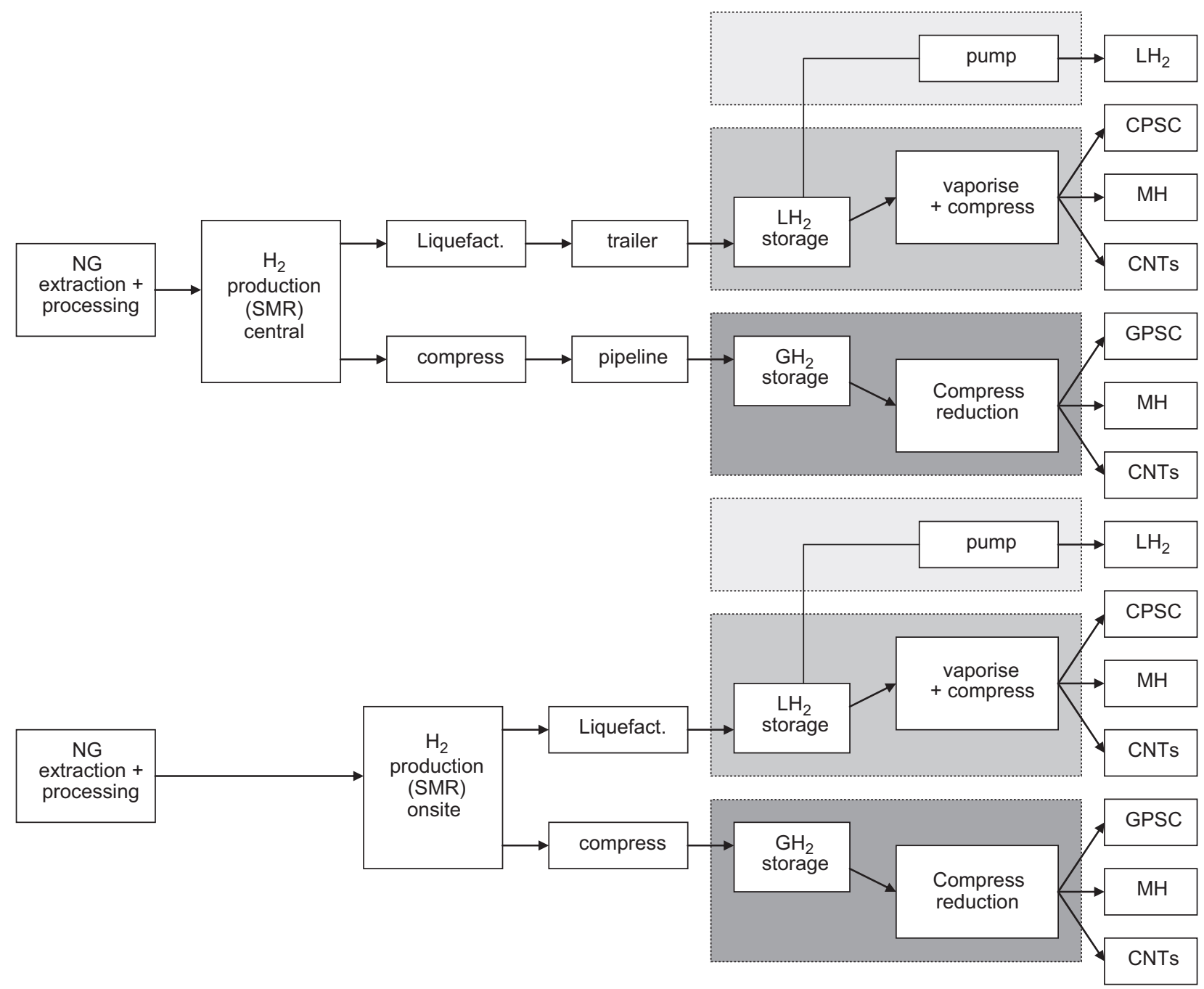

Fig. 1. Overview of assessed chains. Chain 1-7 are supplied by centrally produced and liquefied (1-4) hydrogen. Chain 8-14 use natural gas onsite to produce and liquefy (8-11) hydrogen. In the chains dark colored boxes indicate different filling station configurations. The top box represents a liquid hydrogen pump, the middle gives the configuration for a liquid supplied and gaseous dispensed system the bottom configuration shows a system for gaseous supply and dispensing.

evaluated. The evaluation comprises detailed calculation of the primary energy use and related cost of the distribution system. Three filling station configurations are considered to meet the required form and conditions of hydrogen for the onboard storage system of the vehicle. These three types comprise a gaseous supplied and two liquid supplied configurations. The vehicles included in the assessment are PEM fuel cell vehicles (FCV) and hydrogen fuelled internal combustion engine vehicles (ICEVs). Both propulsion type vehicles are assessed in a hybrid $^{2}$ form also, resulting in a total of four vehicle types assessed with respect to their fuel economy and driving properties. The resulting 14 chains are presented in Fig. 1.

Of key importance for an assessment focussed on differences between supply chains, filling station configurations, onboard storage and propulsion technologies is the inclusion of pressure

\footnotetext{
${ }^{2}$ PEM fuel cell operating on $100 \%$ compressed hydrogen with electric drive train with addition of a battery to meet peak demand. Hydrogen ICE with $\mathrm{CV}$ transmission plus battery and electric motor, running in parallel.
}

differences along the chain, and energy (heat) required to free hydrogen from the storage medium onboard the vehicle. This is explicitly taken into account in the specifications of the chains and included in the calculations.

\section{Data and assumptions}

\subsection{Onboard storage technologies}

Four hydrogen onboard storage technologies are included in the analysis. The four technologies are chosen from a range of possible storage technologies and are considered representative with respect to cost and energy efficiency performance in the well-to-wheel chain. Both the gaseous and the liquid onboard storage technologies are included in the analysis as key reference technologies. These reference technologies represent R\&D efforts by some major car manufacturers (e.g. [12]). With respect to advanced options for hydrogen onboard storage, gas 
Table 1

Property overview of hydrogen storage systems considered in this analysis

\begin{tabular}{|c|c|c|c|c|c|c|}
\hline \multirow[t]{2}{*}{ Storage medium } & \multirow[t]{2}{*}{ Pressurized $\mathrm{H}_{2}$} & \multirow[t]{2}{*}{ Liquid $\mathrm{H}_{2}$} & \multirow[t]{2}{*}{ Gas on solid adsorbents } & \multirow[t]{2}{*}{ Chemical storage } & \multicolumn{2}{|l|}{ Reference } \\
\hline & & & & & Gasoline & Diesel \\
\hline Volumetric density $\left(\mathrm{kg} \mathrm{H}_{2} / \mathrm{m}^{3}\right)$ & $23.2-39.4^{\mathrm{a}}$ & 67.7 & $62^{\mathrm{e}}$ & $73-125^{\mathrm{b}}$ & 88 & 134 \\
\hline Gravimetric density ( $\mathrm{kg} \mathrm{H}_{2} / \mathrm{kg}$ storage medium) & $2-8.5^{\mathrm{b}}$ & $6-13^{c}$ & $0-10^{\mathrm{a}, \mathrm{b}}$ & $1.3-14^{\mathrm{b}}$ & 12.6 & 14 \\
\hline Storage tank weight ${ }^{\mathrm{f}}(\mathrm{kg})$ & $134-29$ & $43-18$ & High-25 & $207-17$ & - & - \\
\hline Typical storage pressure (MPa) & $20-69$ & $0.01-2$ & $0.07-11.35$ & $3-6$ & - & - \\
\hline Typical storage temperature $(\mathrm{K})$ & $273-313$ & 20.3 & $80-700$ & $273-373$ & - & - \\
\hline Leakage and boil-off (\%/day) & - & $0.3-0.5^{\mathrm{d}}$ & No leakage & No leakage & - & - \\
\hline Energy required to free $\left.\mathrm{H}_{2}(\mathrm{MJ} / \mathrm{kg} \mathrm{H})_{2}\right)$ & - & - & - & $17.28^{\mathrm{g}}$ & - & - \\
\hline
\end{tabular}

a 23.2 at 345 bar to 39.4 at 690 bar.

${ }^{\mathrm{b}}[19]$ - For pressurized storage two different types are distinguished; between 2 and $5 \mathrm{~kg} \mathrm{H}_{2} / \mathrm{kg}$ for pressurized storage in steel cylinders and between 7 and $8.5 \mathrm{~kg} \mathrm{H}_{2} / \mathrm{kg}$ for pressurized storage in composite material cylinders.

${ }^{\mathrm{c}}[19]$ - For storage and metal hydrides a wide range is given $2\left(\mathrm{LaNi}_{5} \mathrm{H}_{7}\right)-14\left(\mathrm{LiBH}_{4}+2 \mathrm{H}_{2} \mathrm{O}\right)$-for $\mathrm{CNTs}$ range between 0 and $3 \mathrm{~kg} \mathrm{H} / \mathrm{kg}_{2}$.

$\mathrm{d}[21]$ Boil of for a $50 \mathrm{~m}^{3}$ storage dewar.

e [22] Range given for single walled nanotubes (SWNTs).

${ }^{\mathrm{f}}$ Storage tank weight is calculated using the gravimetric densities from the table and the minimum storage requirement of $2.73 \mathrm{~kg} \mathrm{H}_{2}$ to have a $350 \mathrm{~km}$ axiradius with a PEM fuel cell electromotor system with an fuel economy of $0.26 \mathrm{kWh} / \mathrm{km}$.

${ }^{g}$ Storage tank weight is calculated using the gravimetric densities from the table and the minimum storage requirement of $2.73 \mathrm{~kg} \mathrm{H}_{2}$ to have a $350 \mathrm{~km}$ axiradius with a PEM fuel cell electromotor system with an fuel economy of $0.26 \mathrm{kWh} / \mathrm{km}$.

on solid adsorbents—carbon nanotubes (CNTs) — and chemical storage — metal hydrides (MHs) — are assessed. These advanced storage options are included in the analysis, because of their favourable characteristics, such as high energy density (distinction made between volumetric ${ }^{3}$ and gravimetric ${ }^{4}$ storage density) and inherently safe way of storage [12]. The main challenge of MHs is their storage weight (discussed in more detail later in this paragraph). As apposed to choosing two actual storage media for the CNTs and the MH, generic characteristics representative for the advanced storage technologies are used in the analysis. The generic characteristics comprise typical pressure requirements at the refuelling station and the gravimetric and volumetric densities. The values are derived from literature ranges, presented in Table 1. The actual values used in the analysis are described further on in this paragraph.

Some additional characteristics are fuelling and storage temperature requirements, and information on the durability, which is important for the economic performance.

Pressurized hydrogen storage is most commonly used today. High pressure storage increases the energy density and is needed to meet the limited storage volume available in a vehicle. The high pressure, however, requires significant compression energy and subsequent investment and operation cost. In literature, a wide pressure range is given for pressurized storage between $345\left(214 \mathrm{MJ} / \mathrm{m}^{3}\right)$ and $690\left(364 \mathrm{MJ} / \mathrm{m}^{3}\right)$ bar [13]. In the analysis a storage pressure of maximum 700 bar is worked with, representing the upper end of the range.

Liquefaction of hydrogen increases the energy density by more than seven times compared to storage under 700 bar. The liquefaction process, however, is very energy consuming,

\footnotetext{
${ }^{3}$ Volumetric density: The volumetric capacity is defined as the amount of gas adsorbed either in mass or in volume divided by the total volume occupied by the adsorbent and the adsorbed gas, i.e. the volume of the container.

${ }^{4}$ Gravimetric density: Defined as the weight percentage of the adsorbed gas to the total weight of the system, including the weight of the gas.
}

influenced partly by the process scale, and can consume up to $40 \%$ of the energy content of the hydrogen [14]. Another challenge in hydrogen storage is the boil-off of hydrogen that makes long storage periods impossible. ${ }^{5}$ The higher energy density is favourable for the volume and weight of the storage tank.

Hydrogen storage in gas on solid adsorbents presents a promising storage medium.

CNs may be a promising material for hydrogen storage, but experimental results to date have been controversial [15]. The quantity of hydrogen that can be stored per unit of volume and mass is the most important aspect for hydrogen storage. Because some experimental results concerning hydrogen storage have not been reproduced, the current status therefore is a bit unclear. For this analysis CNTs are chosen. Other gas on solid adsorbtion media include, glass microspheres and buckyballs, etc. Because of the extensiveness of different media, single walled, multiwalled, etc., and storage properties we do not present a discussion on a preferred option. Rather the aim of this study is to identify a range of characteristics on the one hand (Table 1) and choose a representative set of values from this range to execute the techo-economic analysis on the other hand.

The CNTs' storage capacity and related gravimetric density is high. Because the hydrogen is bond to the surface when stored it is expected to be inherently safe [6]. The pressure for filling is relatively low, providing an advantage compared to pressurized storage. In the analysis the pressure for filling is chosen at 75 bar, within the range 71 and 82.4 bar given by James et al. [10].

\footnotetext{
${ }^{5}$ Due to the low temperature under which liquid hydrogen $\left(\mathrm{LH}_{2}\right)$ is stored and the temperature difference with ambient temperatures, the stored hydrogen will gradually boil. Because of the boiling, pressure builds up, this pressure is released by a high pressure vent. In the liquid storage tanks included in the analysis a boil-off rate of between $0.3 \%$ and $0.5 \% /$ day is used [20].
} 

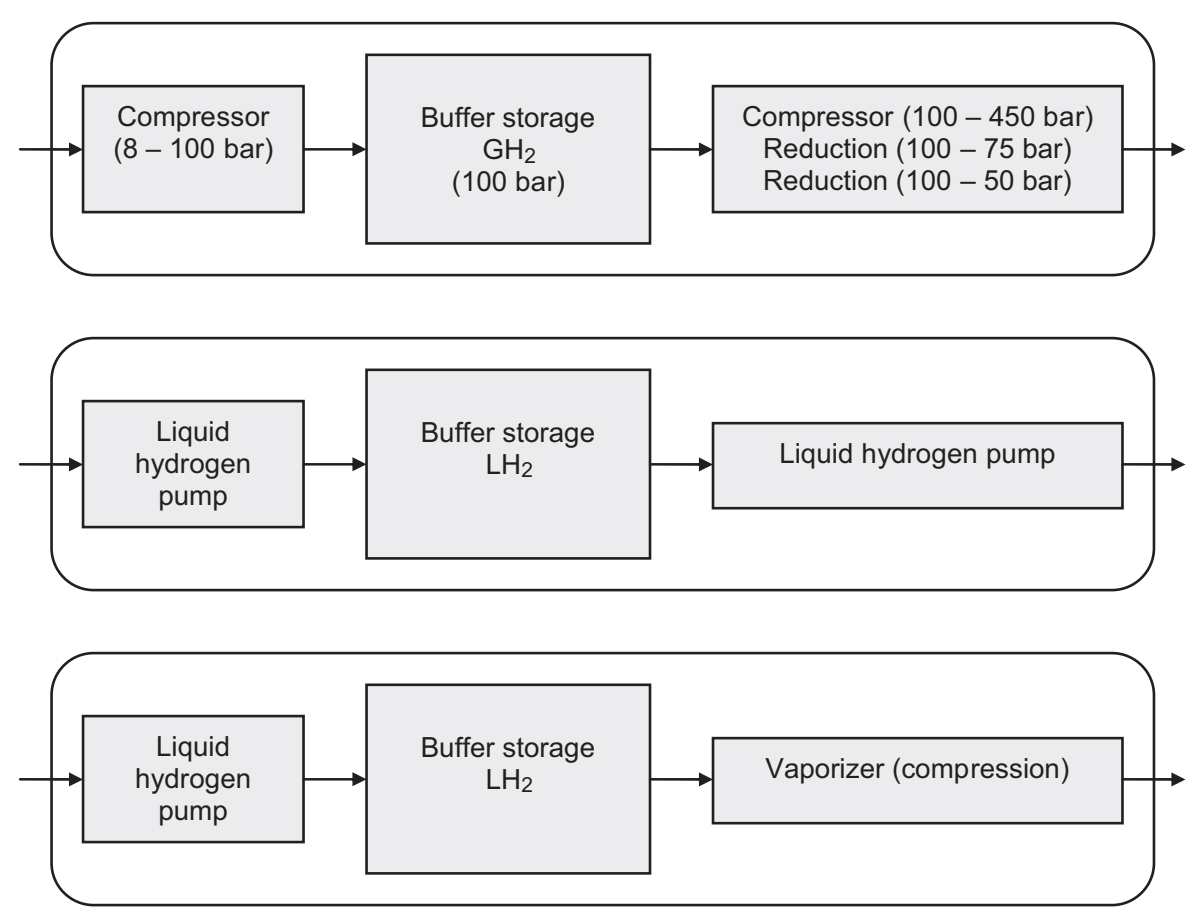

Fig. 2. Filling station configurations.

The fourth storage technology included in the analysis is a $\mathrm{MH}$. A large number of metals and metal alloys can combine with hydrogen to form MHs. The hydrogen absorbing capacity is influenced by pressure and temperature. When hydrogen gas comes into contact with the metal (alloy) surface, often treated with a catalyst, the hydrogen gas dissociates in atomic hydrogen which diffuses into the metal grid. Heat is exhausted upon absorption and required to free hydrogen from the grid when desorbed [16]. Since heat is required to release the hydrogen it is assumed to be inherently safe [5]. The heat produced by the fuel cell or ICEV is used to dissociate hydrogen from the MH [17].

The absorption rate of MHs is depending on the pressure and temperature under which the $\mathrm{MH}$ is brought in contact with the hydrogen gas, with temperature and pressure being inversely related. The pressure range lies between low pressures of 21-23 bar ${ }^{6}$ and highs of 80 bar [18], see Table 1. As a representative pressure $50 \mathrm{bar}$ is assumed.

The effect of storage weight on fuel economy is not quantitatively taken into account in this analysis, as is done in some other studies (e.g. [19]). The impact of storage weight on the performance is, however, addressed in the discussion of the results, based on analysis of a comparable study.

\subsection{Filling station configurations}

The filling station dimensions are derived from the supply of a large conventional filling station. The station is assumed to serve 500 cars daily. The average car has an assumed

\footnotetext{
${ }^{6}$ Hydrogen absorption of nanocrystalline $\mathrm{Na}_{2} \mathrm{LiAlH}_{6}$ without catalyst at near-equilibrium conditions.
}

axiradius on one tank of $350 \mathrm{~km}$. With an average fuel economy for a PEM fuel cell fuelled vehicle of $1150 \mathrm{~kg}$ of $0.94 \mathrm{MJ} / \mathrm{km}^{7}(1.94 \mathrm{MJ} / \mathrm{km}$ for an ICEV) [22], following the standard European driving cycle the 'New European Driving Cycle' (NEDC) [35]. The average full tank holds $2.73 \mathrm{~kg} \mathrm{H}_{2}$. Multiplied by 500 cars a day, which is a typical throughput for a relatively large fuelling station, the total hydrogen demand per filling station is $1366 \mathrm{~kg} \mathrm{H}_{2}$ per day (or $4.6 \mathrm{TJ} \mathrm{H}_{2}$ per year). The figure, of $2.73 \mathrm{~kg} \mathrm{H}_{2}$, is also used for the driving trains with lower engine efficiencies and hence higher demand.

Three filling station configurations are considered, shown in Fig. 2. The filling stations can be supplied by gaseous or $\mathrm{LH}_{2}$. The filling stations have to dispense the hydrogen to the four assessed onboard storage media; high pressure storage (700 bar), MH (75 bar), CNTs (50 bar) and liquid.

The hydrogen from the transportation pipeline enters the filling station at 8 bar. First, a $160 \mathrm{~kW}$ reciprocating compressor compresses the hydrogen to 100 bar [23] buffer storage pressure. From the buffer storage pressure, the onboard storage systems can be supplied. For the high-pressure storage, $1042 \mathrm{~kW}$ hydraulic booster compressors are needed to meet the 700 bar onboard storage pressure. For the MHs (75 bar) and CNTs ( $50 \mathrm{bar}$ ) the buffer storage pressure can be reduced, requiring expanders that do not need extra energy.

The hydrogen is delivered to the filling station in liquid form by trucks. From the truck the $\mathrm{LH}_{2}$ is pumped into the (buffer)

\footnotetext{
${ }^{7}$ The fuel economy figures are based on CONCAWE study [22]. Two aspects are influential for the fuel economy; the vehicle characteristics and the assessed driving cycle. All simulations are based on a common, "virtual" vehicle, representing a typical European compact size 5-seater sedan; weight is $1250 \mathrm{~kg}$, comparable to e.g. Volkswagen Golf. The theoretical vehicle is used as a tool for comparing the various fuels and associated technologies.
} 
storage at the filling station. To dispense the hydrogen to the vehicle, $101 \mathrm{~kW}$ pumps [24] are used. Since no pressure differences or other conditioning has to be realized at the filling station site only energy for the pumps is needed.

Hydrogen is supplied in liquid form to the filling station buffer storage. From the liquid buffer storage the hydrogen is vaporized and pressurized to meet the required pressure for the onboard storage system. Pressurizing is done under expansion and vaporization of the liquid requiring no extra compression energy.

\subsection{Supply chain processes}

\subsubsection{Electricity production}

The electricity production generation is assumed to come from the Dutch electricity mix 2020 [25]. All processes using electricity use this electricity mix, with an overall efficiency of 55.3\% ${ }^{8}$ The unit price for delivered electricity is assumed $0.05 € / \mathrm{kW} \mathrm{h}^{9} \quad[26]$.

\subsubsection{Natural gas extraction, processing and transport}

The hydrogen production chains are based on a natural gas input. It is expected that in the year 2020 a large quantity of natural gas is imported from Russia [25] and subsequently the extraction and processing is carried out there. Important processing includes the removal of heavier hydrocarbons and contaminations such as $\mathrm{H}_{2} \mathrm{~S}$. For the processing heat is required, provided by the burning of natural gas. The extraction and processing make use of electricity, considered to come from the Dutch electricity mix. ${ }^{10}$ The natural gas is transported and imported from Russia through a distribution pipeline. The transport over a distance of $7000 \mathrm{~km}$ has an overall efficiency of $97.7 \%$, the efficiency losses are primarily due to leakage, ${ }^{11}$ in the piping and compressor stations and the work done by natural gas fuelled compressors. From the Dutch border a $250 \mathrm{~km}$ pipeline transports the natural gas to the Rotterdam harbour area in the Netherlands. For transport compression, work is required delivered by a natural gas fuelled compressor with an efficiency of $33 \% .{ }^{12}$ In the pipeline transport some losses occur due to leakages. The natural gas cost are considered to be a result of the global market of oil and gas trading, not related to

$855.3 \%$ efficiency forecast for total electricity mix of the Netherlands for 2020 [25]. The relative shares for the different feedstocks are as follows; natural gas $(84 \%)$, wind power (2\%), biomass (7\%), coal (hard) $(5 \%)$, mineral oil $(2 \%)$, hydro $(0.05 \%)$. Wind power and hydro power are considered to have an efficiency of $100 \%$.

${ }^{9}$ No distinction is made in the electricity unit price between small and large scale buyers, because of the difficulty to predict price differences on the basis of the amount purchased. In the sensitivity analysis, however, the effect of electricity unit price fluctuations on the total outcome is shown.

${ }^{10}$ Although this obviously does not reflect the actual situation this figure is used because no detailed Russian electricity mix is known per region. Furthermore, the Russian electricity use is considered of marginal impact on the overall assessment.

${ }^{11}$ Although some estimates of the methane emission during production and transport of natural gas within Russia and from Russia to the EU are substantial, Lelieveld et al. [27] conclude after extensive measurements that the average leakage percentage is $0.7 \%$ (range $0.4-1.6 \%$ ).

12 Defined as primary energy in to establish the required output of work. specific supply chains and related process. For the calculations the unit cost for natural gas is assumed $€ 3.35 / \mathrm{GJ}^{13}$ [26].

\subsubsection{Hydrogen production and liquefaction}

Large scale hydrogen production takes place centralized, for example in the Rotterdam harbour area, using a large steam methane reformer ${ }^{14,15}$ (SMR) of $840 \mathrm{MW}$. For hydrogen purification a pressure swing adsorption (PSA) unit is integrated to obtain a purity of $99.999 \% \mathrm{H}_{2}$, required in the PEM fuel cell systems. The overall energy efficiency of large-scale hydrogen production (Linde) is $73 \%$. The investment costs are presented in Table 2.

Small scale hydrogen production on the filling station (onsite) make use of a small scale steam reformer of $2.7 \mathrm{MW}$ with an efficiency of 69\% (Haldor Topsoe).

Liquefaction of hydrogen is considered only for some chains. The liquefaction installation is assumed to be integrated in the hydrogen production facility, requiring no transport of the hydrogen gas from the production facility. A large-scale liquefaction plant of $450 \mathrm{MW}$ of hydrogen throughput is used. The efficiency and related cost for the liquefaction process is especially sensitive to process scale, compared to production. The energy use for liquefaction is $0.35 \mathrm{MJ}_{\mathrm{e}} / \mathrm{MJ} \mathrm{H}_{2}$ resulting in an efficiency of $61.2 \%$ on a LHV basis for centralized liquefaction. Electricity comes from the Netherlands electricity mix 2020. For onsite liquefaction this figure is down scaled [14], for a $1.7 \mathrm{MW}$ plant to $0.63 \mathrm{MJ}_{\mathrm{e}} / \mathrm{MJ} \mathrm{H}_{2}$, with an overall efficiency of $40.6 \%$.

\subsubsection{Hydrogen transport}

The assessed case is representative for densely populated area's in western Europe. In this analysis it is assumed that the hydrogen is distributed over a distance of $100 \mathrm{~km}$. For centrally produced hydrogen two modes of transportation are assessed; gaseous pipeline and liquid truck transport (Table 3). For the pipeline a large distribution pipeline, pressure $60 \mathrm{bar}^{16}$ over

13 Electricity and natural gas prices supplied from the grid are based on prices for small industrial users in the EU which correspond to the scales used in the analysis in this paper [28].

${ }^{14}$ Steam methane reforming (SMR): The basic SMR process uses steam $\left(\mathrm{H}_{2} \mathrm{O}_{(\mathrm{g})}\right)$ to heat natural gas to approximately $850^{\circ} \mathrm{C}$ over a nickel catalyst bed, yielding a mixture of $\mathrm{CO}$ and $\mathrm{H}_{2} \mathrm{O}$. The mixture is then cooled and catalyzed with steam again to yield pure hydrogen and $\mathrm{CO}_{2}$ [29].

$15 \mathrm{~A} \mathrm{CO}_{2}$ capture unit can be integrated in the installation. With an MDEA (methyl diethanolamine) after shift $\mathrm{CO}_{2}$ unit the capture efficiency is $85 \%$, with an MEA (monoethanolamine) after furnace $\mathrm{CO}_{2}$ capture unit up to $90 \%$. The cost for the SMR process equipped with such a capture unit is $17 \%$ higher compared to a process without a capture unit [30]. The IPCC puts the cost penalty of the integration of a $\mathrm{CO}_{2}$ capture unit in an SMR process between $18 \%$ and 33\% [31]. The conversion efficiency of an SMR process equipped with an MEA unit suffers $13 \%$ point (from $74 \%$ to $61 \%$ ) and an MDEA unit $3 \%$ point (from $76 \%$ to $73 \%$ ) [30].

$1660 \mathrm{bar}$ is currently used in natural gas transport pipelines. The consideration is as follows. The realized throughput depends on the pipeline diameter and the pressure under which it is transported. At higher pressures than 60 bar a thicker pipeline wall is required, resulting in higher metal cost [32]. If, however, the diameter is getting larger the material cost rises as well and it becomes practically less efficient. Because it is a consideration between pressure, wall thickness, pipeline diameter and throughput the ideal properties do not depend on which gas is transported but on the relations between these properties. Hence an optimum is achieved at 60 bar. 
Table 2

Cost overview of the hydrogen production and liquefaction technologies considered

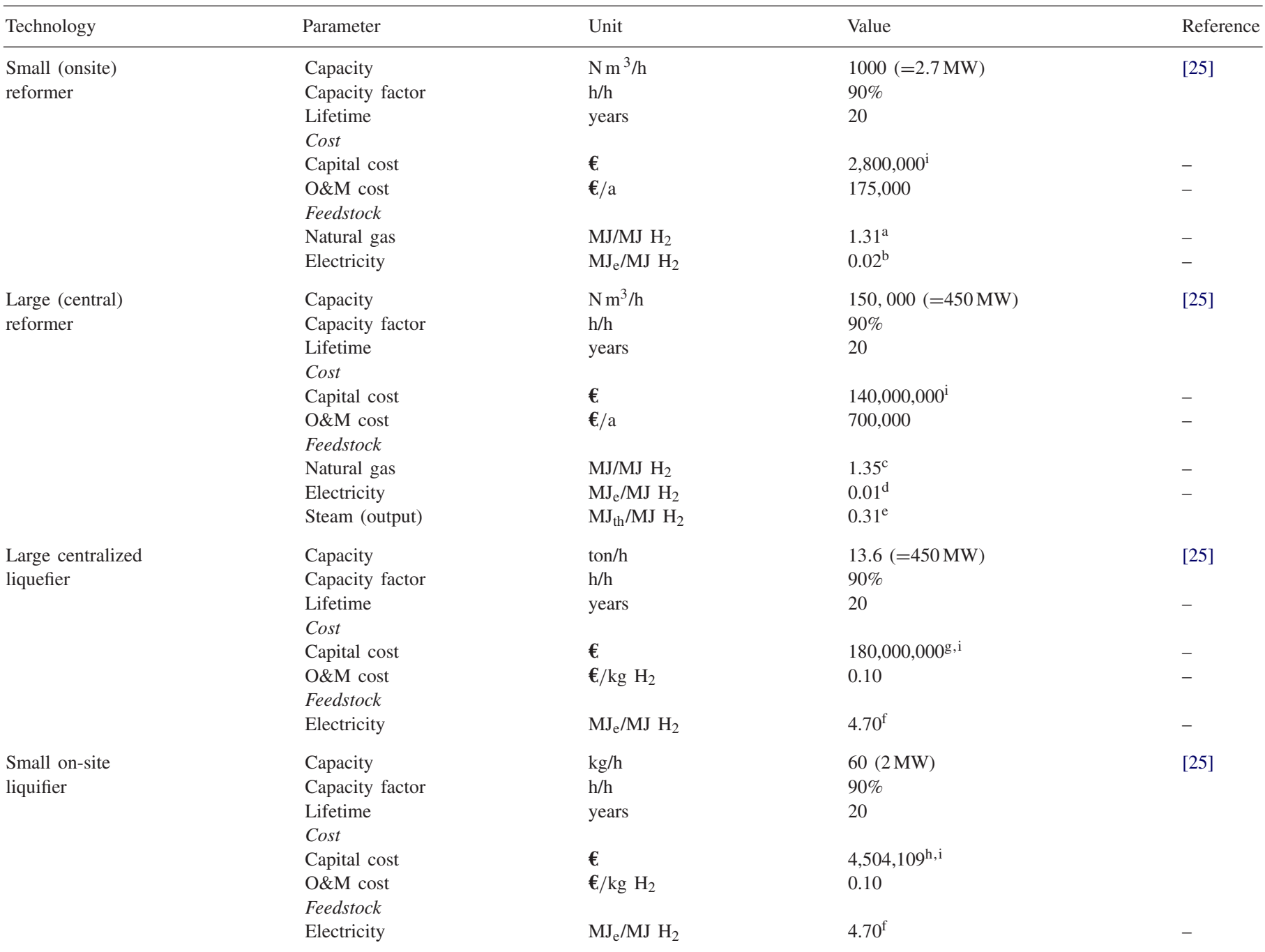

${ }^{a} 420 \mathrm{~N} \mathrm{~m}^{3} \mathrm{NG} / \mathrm{h}$ per $1000 \mathrm{Nm}^{3} \mathrm{H}_{2} / \mathrm{h}$.

${ }^{\mathrm{b}} 0.07 \mathrm{MWh}_{\mathrm{e}}$ per $1000 \mathrm{~N} \mathrm{~m}^{3} \mathrm{H}_{2} / \mathrm{h}$.

${ }^{\mathrm{c}} 65,000 \mathrm{~N} \mathrm{~m}^{3} \mathrm{NG} / \mathrm{h}$ per $150 \mathrm{~N} \mathrm{~m}^{3} \mathrm{H}_{2} / \mathrm{h}$.

${ }^{d} 5 \mathrm{MWh}_{\mathrm{e}}$ per $150,000 \mathrm{~N} \mathrm{~m}^{3} \mathrm{H}_{2} / \mathrm{h}$.

${ }^{\text {e}}$ The steam output is a useful energy output and is beneficial to the overall efficiency. In terms of economics this stream is not included. $140 \mathrm{MW}_{\text {th }}$ per $150,000 \mathrm{~N} \mathrm{~m}^{3} \mathrm{H}_{2} / \mathrm{h}$.

${ }^{\mathrm{f}} 1 \mathrm{~kW} \mathrm{~h} / \mathrm{L} \mathrm{H} \mathrm{H}_{2}$.

g $\$, 98$ converted to $\boldsymbol{\epsilon}_{, 05}$.

${ }^{\mathrm{h}}$ Capital cost downscaled using large liquefier data and scale factor $(0.68)$ for general equipment assumed: $\operatorname{Cost}_{\text {new }}=\operatorname{Cost}_{\text {known }}\left(\operatorname{Scale}_{\text {new }} / \mathrm{Scale}_{\mathrm{known}}\right)^{R}$.

${ }^{\mathrm{i}}$ The annuity factor is calculated based on the after tax real rate of return $(r=10 \%)$, the inflation rate $(i=2 \%)$ and the specific lifetime $(n)$ of the installation considered. The lifetime is the economic lifetime. With $d=r(2 i+r)$ annuity_factor $=d / 1-\left(1 /(1+d)^{n}\right)$.

$100 \mathrm{~km}$ and a diameter of $50 \mathrm{~cm}$ is considered [26]. From the main transmission pipeline a medium pressure pipeline, pressure $8 \mathrm{bar}$, of $5 \mathrm{~km}$ transports and diameter of $7.5 \mathrm{~cm}$ the hydrogen to the filling station (buffer storage) [26]. Hydrogen-fuelled compressors, using hydrogen directly from the pipeline, with an efficiency of $30 \%,{ }^{17}$ deliver mechanical work. The mechanical

${ }^{17}$ Same efficiency as natural gas fired compressors assumed. The mechanical efficiency is assumed to be $90 \%$ the work is delivered by a hydrogen burned gas turbine or by electricity. The efficiency of 30\% stated is the quotient between the work delivered and the primary feedstock input. work is needed to overcome friction losses. ${ }^{18}$ No mechanical work is needed for the $5 \mathrm{~km}$ end delivery pipeline, since friction losses are compensated by the pressure difference.

As an alternative to gaseous hydrogen transport through pipelines, tube trailer transport can be used. To ensure comparability with pipeline distribution a transport distance of $100 \mathrm{~km}$ is assumed. The hydrogen is tanked into the tank trailer from the liquefaction (buffer) storage. The trailer stores approximately $50 \mathrm{~m}^{3} \mathrm{LH}_{2}$ (i.e. $3389 \mathrm{~kg} \mathrm{H}$ ). Boil-off in a

\footnotetext{
${ }^{18}$ A simple pipeline configuration is assumed, consisting of a straight $100 \mathrm{~km}$ pipeline without ramifications.
} 
Table 3

Cost factors for hydrogen pipeline transport

\begin{tabular}{|c|c|c|c|c|}
\hline Technology & Parameter & Unit & Value & Reference \\
\hline \multirow[t]{8}{*}{ Large transmission pipeline } & Length & $\mathrm{km}$ & $100^{\mathrm{a}}$ & {$[31]$} \\
\hline & Diameter & $\mathrm{m}$ & $0.5^{\mathrm{a}}$ & \\
\hline & Capacity & $\mathrm{MN} \mathrm{m}^{3} / \mathrm{h}$ & $2.5^{\mathrm{b}}$ & \\
\hline & Allocation factor & $\mathrm{h} / \mathrm{h}$ & $0.02 \%^{\mathrm{c}}$ & \\
\hline & Lifetime & years & $30^{\mathrm{d}}$ & - \\
\hline & Cost & & & \\
\hline & Capital cost per unit of length & $€_{/} / \mathrm{km}$ & $1,790,000^{\mathrm{e}}$ & \\
\hline & Total capital cost & $€$ & $3,580,000^{f}$ & \\
\hline \multirow[t]{7}{*}{ Small delivery pipeline } & Length & $\mathrm{km}$ & $5^{\mathrm{a}}$ & {$[31]$} \\
\hline & Diameter & $\mathrm{m}$ & $0.075^{\mathrm{a}}$ & \\
\hline & Capacity & $\mathrm{kN} \mathrm{m}^{3} / \mathrm{h}$ & $6.7^{\mathrm{b}}$ & \\
\hline & Lifetime & years & $30^{\mathrm{d}}$ & - \\
\hline & Cost & & & \\
\hline & Capital cost per unit of length & $€ / \mathrm{km}$ & $347,550^{\mathrm{e}}$ & - \\
\hline & Total capital cost & $€$ & $1,740,000^{\mathrm{g}}$ & \\
\hline
\end{tabular}

\footnotetext{
${ }^{\mathrm{a}}$ Assumption.

${ }^{\mathrm{b}}$ Calculation.

${ }^{\mathrm{c}}$ Demand per filling station $\left(1365 \mathrm{~kg} \mathrm{H}_{2} /\right.$ day, see calculation paragraph 2.2$)$ divided by total capacity pipeline. This gives the proportion of the total pipeline capacity that is required for the actual demand on one filling station.

${ }^{\mathrm{d}}$ Lifetime is assumed to be 30 years. This corresponds to the depreciation period more than to the actual pipeline lifetime.

${ }^{\mathrm{e}}$ Calculation based on parker, 2003 total capital cost $=4.82 \mathrm{D}-2.48 \mathrm{D}^{2}$ (D is pipe diameter).

${ }^{\mathrm{f}}$ Capital cost per unit length multiplied by the total length and by the allocation factor.

${ }^{g}$ Multiplication of the capital cost per kilometre and the length of the pipeline.
}

$50 \mathrm{~m}^{3}$ storage dewar is $0.4 \% /$ day $(0.3-0.5 \% /$ day $)$, half a day of storage in the truck is assumed, resulting in a boil-off of $0.2 \%$ per delivery. The truck is diesel fuelled on a $100 \mathrm{~km}$ (one way, $200 \mathrm{~km}$ return) driving cycle. The truck's weight equals 40 ton.

Concerning the cost for $\mathrm{LH}_{2}$ truck transport the study of Amos [9] is used. Two factors are decisive for the cost, the quantity that is and the distance over which the hydrogen is transported. The study by Amos provides cost figures for a wide range of transport distances. The distance assessed in this paper, of $100 \mathrm{~km}$, is not assessed. This cost figure therefore is obtained by linear interpolation of cost ranges for the 16 and $161 \mathrm{~km}$ distances. For a transport distance of $16 \mathrm{~km}$ the transport cost are estimated between the $0.24-1.60 \$ / \mathrm{GJ} \mathrm{H}_{2}$ and for $161 \mathrm{~km}$ between $0.52-1.84 \$ / \mathrm{GJ} \mathrm{H}_{2}$ [9]. By interpolation this becomes for a transport distance of $100 \mathrm{~km}$, between the 0.40 and $1.74 \$ / \mathrm{GJ}$ $\mathrm{H}_{2}$. Per unit of mass this becomes $0.048-0.209 \$ / \mathrm{kg} \mathrm{H}_{2}$.

\subsubsection{Buffer storage}

On the filling station site a buffer storage tank is required to meet fluctuations between demand and supply. Depending on the transported and dispensed form these can be gaseous and liquid storage tanks. The (buffer) storage dewars require space on the filling station site, cost additional energy because of compression energy needed and are subject to leakage. The leakage is minor due to limited dwelling time and a relatively large storage volume. ${ }^{19}$ The dimensioning of buffer storage requires insight in the demand and supply fluctuations in time, and most importantly peak demand in these fluctuations.

\footnotetext{
19 Boil off increases with a high surface to volume ratio. This ratio decreases with increasing tank size. Since the tank are relatively large, boil off is limited.
}

From the delivery pipeline the pressure ( 8 bar) is raised by a hydrogen compressor to 100 bar under which it is stored. Storage pressure is relatively low in the buffer storage, to limit energy losses due to pressure reduction for the filling pressures for MHs and CNTs. Under low-pressure conditions, required storage volume is high. A typical dimension for a one day buffer supply, for the case filling station, is $340 \mathrm{~m}^{3}\left(1365 \mathrm{~kg} \mathrm{H}_{2}\right.$ at 100 bar) demand. It is assumed that no gaseous storage facility is required because of the storage potential in the hydrogen gas supply infrastructure. For liquid storage a storage volume of one days' filling station throughput is assumed of about $21 \mathrm{~m}^{3}$, which follows from the daily throughput calculation made in paragraph 3.2.

\subsubsection{Reference scenario}

For comparison a reference scenario is calculated, derived from the CONCAWE [22] study and a study by Hamelinck [33]. Three types of reference vehicles are included in the assessment; a gasoline ICE, a diesel ICE and a sugarcane ethanol ICE for the reference year 2010 [22]. The gasoline and diesel ICE chains enable comparison with the current (or near future) status of conventional propulsion technologies and fuels. The sugarcane ethanol reference is a representative cost and primary energy use bio-fuel with an average performance and therefore enables (indicative) comparison between the assessed chains and bio-fuels.

The total energy consumption from well-to-wheel is the sum of the well-to-tank pathway for gasoline and for the tankto-wheel a fuel consumption. The well-to-tank energy consumption is the same for all three vehicle types and fuel options considered with $0.135 \mathrm{MJ}_{\mathrm{p}} / \mathrm{MJ}_{\mathrm{f}}$. The tank-to-wheel energy consumption differs with $1.90 \mathrm{MJ}_{\mathrm{f}} / \mathrm{km}$ for the gasoline ICE and 
1.62 for the gasoline and bio-ethanol ICE hybrid option. The total for gasoline ICE is $2.16 \mathrm{MJ}_{\mathrm{p}} / \mathrm{km}$ and for the gasoline ICE hybrid $1.76 \mathrm{MJ}_{\mathrm{p}} / \mathrm{km}$.

\section{Results and discussion}

\subsection{Energetic performance: well-to-tank and well-to-wheel primary energy use}

In Fig. 3, the energy use for fuel delivery $\left(\mathrm{MJ}_{\mathrm{p}} / \mathrm{MJ}_{\mathrm{H}_{2}}\right)$ and for driving energy $\left(\mathrm{MJ}_{\mathrm{p}} / \mathrm{km}\right)$ are presented. The fuel deliverance energy use comprises the energy use of the supply chain from natural gas extraction, processing, distribution and hydrogen production (light grey) to, in some cases, liquefaction (darker grey), hydrogen distribution (black) and finally dispensing on the filling station to the actual storage in the onboard storage medium (white). Every stacked bar column represents the energy use, divided per process step in the chain, and per onboard storage technology (with $\mathrm{LH}_{2}=$ liquid cylinder storage, $\mathrm{CGH}_{2}=$ compressed gaseous hydrogen storage, $\mathrm{MH}$ storage and CNTs storage). The columns shown represent the result for the best performing option car transmission system (FCV hybrid), with the variation bars indicating the performance range, including all other options; FCV, ICE hybrid and ICE, the latter having the lowest efficiency. The stacked bar columns present the primary energy use for the well-to-tank and well-to-wheel. The variation bars only indicate the range that applies to the driving energy use (right) axis.

What stands out, in Fig. 3, is that the assessed chains are in the same order of magnitude as are the two fossil reference chains for diesel and gasoline. Centralized hydrogen production and liquefaction outperforms onsite hydrogen production and liquefaction by $20 \%$ on primary energy input . The advantage of higher efficiencies for large scale processes apparently more than compensates the need for pipeline or over the road distribution. For the centralized case, the two advanced onboard storage technologies with $0.104 \mathrm{MJ}_{\mathrm{p}} / \mathrm{km}$ perform $22 \%$ better as compared than to the conventional (compressed gaseous and liquid) onboard storage technologies with $0.127 \mathrm{MJ}_{\mathrm{p}} / \mathrm{km}$.

Concerning the distribution of primary energy consumption for driving, two processes consume over $80 \%$ of the energy inputs in all chains, the hydrogen production (light grey) and the liquefaction (darker grey). The energy use of hydrogen distribution (black) and the filling station handling (white) are minor contributing factors. Even the liquid truck transport, considered energy consuming, in the centralized scenario does only contribute just over $2 \%$ to the total. The filling station handling, in the centralized gaseous dispensed chains contributes to the total for $9 \%$ for the $\mathrm{MH}$ and CNTs and up to $21 \%$ for the compressed gaseous hydrogen storage.

\subsection{Cost analysis: well-to-tank and well-to-wheel cost performance}

In Fig. 4 the fuel delivered and dispensed cost (well-to-tank) and the driving cost (well-to-wheel) are presented. The fuel delivered and dispensed cost, shown in the left hand graph, comprise the cost for natural gas extraction, processing, distribution and hydrogen production (light grey), for liquefaction (white), the hydrogen distribution (darker grey) and the filling station dispensing (black). The driving cost, shown in the right hand

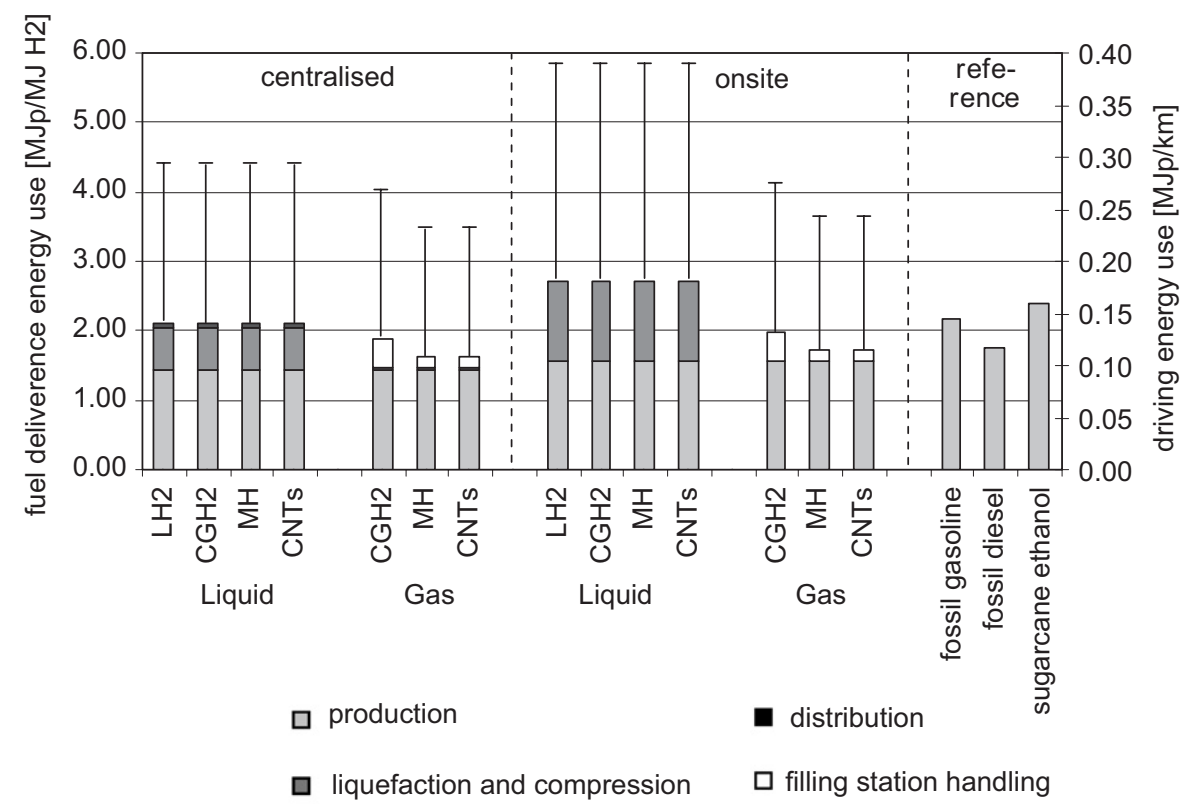

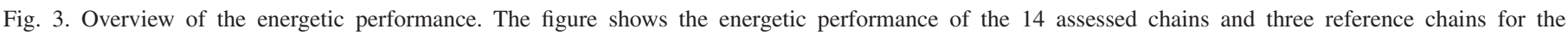

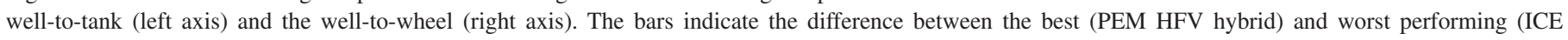
FCV) option. 
fuel delivered and dispensed cost [€/GJ]

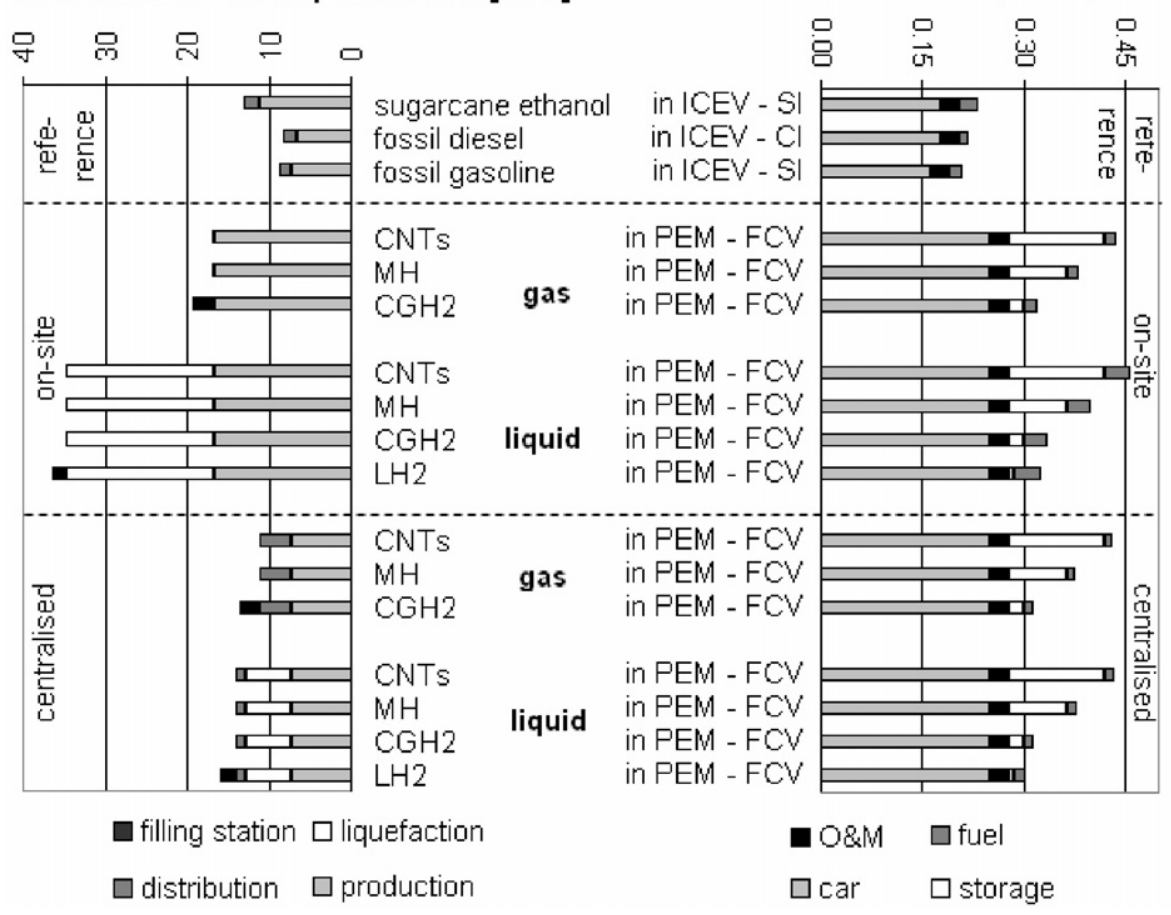

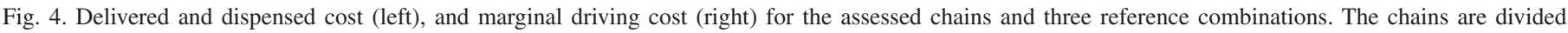

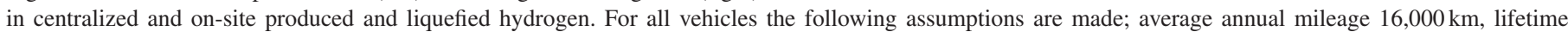

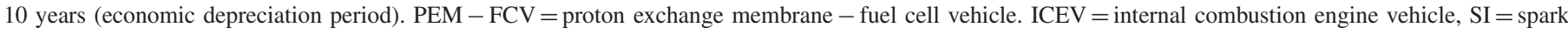
ignition and $\mathrm{CI}=$ compression ignition.

graph, comprise the cost for the car expenditure (light grey), the Operation and Maintenance (black), the hydrogen onboard storage medium cost (white) and the delivered and dispensed fuel cost (darker grey). The latter figure (darker grey in the right hand graph) is the total of the results in the left hand graph, hence clarifying the share of the well-to-tank cost share in the total driving cost.

Focussing on the well-to-tank (left hand axis) cost first, it shows that the cost for production and liquefaction of hydrogen on the filling station (onsite) are higher than centralized production and liquefaction. In the case of liquefaction, the cost is more than double onsite compared to centralized production and liquefaction. Furthermore, the fuel production for hydrogen is in all cases substantially higher than the two fossil and the bio-fuel reference cases. The distribution of the respective processes and their related cost, it is apparent that the production and the liquefaction incorporate the majority of the cost. The distribution cost are higher for pipeline distribution, with $28.5 \%$ of the least energy consuming chains, than are the distribution cost for liquid truck transport, comprising only $7.7 \%$ of the cost. For the filling station handling the high pressure storage does contribute to the total considerably, with $18.4 \%$ of the centralized pipeline distributed chain, especially due to the relatively high booster compressor cost.

The driving cost, shown in the right hand graph, shows the total well-to-tank cost as the fuel cost (darker grey), the storage cost (white), the operation and maintenance cost and the car expenditure. Car expenditure shows to be the decisive cost factor in the driving cost of a car, whether conventional (ICE run on fossil or bio-fuels) or fuel cell driven. The fuel cell car costs are $41 \%$ higher than the compression ignition ICE and $54 \%$ than spark ignition car cost.

The focus of the study was the impact of onboard storage technologies on the performance. Concerning the economic performance, the two advanced onboard storage options appear to have high costs, of $8.7 € \mathrm{c} / \mathrm{km}$ for $\mathrm{MH}$ and $14.4 € \mathrm{c} / \mathrm{km}$ for CNTs, on top of the already higher FCV powered cars cost of $27.5 € \mathrm{c} / \mathrm{km}$ (including O\&M cost). The fossil gasoline reference case the car expenditure cost, including O\&M, are $18.5 € \mathrm{c} / \mathrm{km}$. The well-to-wheel cost for the fuel only play a marginal role in the per kilometre cost, placing the main focus on the cars capital expenditure and storage material cost.

\subsection{The PEM fuel cell and ICE hybrid}

The effect of vehicle mass on the fuel economy can be of influence on the performance of the energetic and economic parameters. Because drive cycle modelling is beyond the scope of this assessment we limit ourselves to some reviewing comments on reference results on vehicle mass influence on the fuel economy. Of great importance in providing an estimate on the influence of vehicle weight on the fuel economy is the required axiradius and hence the amount of hydrogen that is to be stored onboard the vehicle. With the assumed axiradius requirement and related onboard storage capacity the effect on the fuel economy will be the highest for MHs with a negative impact of 
about $2.9 \% 20$ (from 0.104 to $0.107 \mathrm{MJ}_{\mathrm{p}} / \mathrm{km}$ ). The effect of energy required to free hydrogen from the storage medium only arises with the MH. For the performance it is important to assess if extra energy (heat) is required to free the hydrogen from the storage medium. The PEM fuel cell delivers a heat surplus during operation, whether this is enough for the adsorption of the MHs depends on the MH and its related desorption energy requirement. If a low or medium $\mathrm{MH}$ is assessed the surplus heat from the PEM fuel cell stack is sufficient for desorption of the hydrogen so that no extra energy is needed [10]. The characteristics chosen for the $\mathrm{MH}$ correspond to the low and medium MHs, hence the condition of desorption by surplus PEM fuel cell heat also applies to the researched case.

\section{Conclusions}

The focus of this research is to assess four onboard storage technologies with respect to their energetic and economic wellto-wheel performance and by doing so being able to identify the outlook for each assessed hydrogen onboard storage technology. The energy well-to-wheel performance of the assessed chains show results which are in the same order of magnitude of the fossil and bio-based reference cases, at least for the best performing PEM-FC hybrid engine technology. The energy performance range is within 0.10 and $0.20 \mathrm{MJ}_{\mathrm{p}} / \mathrm{km}$, the gasoline reference case at $0.14 \mathrm{MJ}_{\mathrm{p}} / \mathrm{km}$. This indicates that in terms of primary energy, the assessed hydrogen pathways do not show a significant advantage over fossil or bio-based fuel use. Although not specifically taken into account in the analysis; based on literature data an estimate of the environmental performance is made. From the European commission Concawe study [22] the greenhouse gas emission factors, ${ }^{21}$ in grams of $\mathrm{CO}_{2}$ equivalent per energy of fuel, give an indication for the environmental impact performance. From the energy analysis' results it is clear that pressurization of the hydrogen consumes the majority of the electricity, which is reflected in a high emission factor ${ }^{22}$ of $98 \mathrm{~g} \mathrm{CO}_{2 \text {-eq. }} / \mathrm{MJ}_{\mathrm{H}_{2}}$. For the liquefied hydro-

20 The vehicle weight of the reference vehicle is $1150 \mathrm{~kg}$. Required axiradius is $350 \mathrm{~km}$, resulting in a required onboard storage capacity of $2.73 \mathrm{~kg}$ $\mathrm{H}_{2}$. For a $\mathrm{MH}$ with a gravimetric density of $5 \%$ this is $54.6 \mathrm{~kg} \mathrm{MH}$ rounded up to $60 \mathrm{~kg}$ for casing, etc. According to the influence of total vehicle weight on fuel economy by Allison and Cole [34] an increase of the vehicle weight of $10 \%$ has a $5.5 \%$ lower fuel economy.

${ }^{21}$ All emission factors are taken from the Concawe study [22]. Emission factors are estimated from the graphs and should therefore be considered estimates.

22 The electricity production related emission factor is based on a European average derived resources mix. Consisting of the sources; nuclear (37.5\%), Coal $(22.4 \%)$, Oil (9.6\%), Gas (15.5\%), Hydro (12.4\%), Wind $(0.4 \%)$, Waste $(1.8 \%)$ and other renewables $(0.3 \%)$ [22]. In the calculations for the energy performance, the electricity resource mix for the Netherlands of 2020 is used differing in composition from the European mix as described here. The electricity mix of the Netherlands of 2020 has an average emission factor of $351 \mathrm{~g} \mathrm{CO}_{2 \text {-eq }} / \mathrm{kWh}$, compared to $430 \mathrm{~g} \mathrm{CO}_{2 \text {-eq }} / \mathrm{kWh}$ used in the Concawe study for the European average. Although the European average has a large non- $\mathrm{CO}_{2}$ production capacity (due to nuclear and hydro), the Netherlands mix has a lower emission factor, most notably because of the large share of natural gas. This on the one hand means one should exercise caution when comparing energy and emission results on the other hand it exemplifies how emissions depend on the used electricity fuel mix. genchains this figure is, due to the extra energy consuming liquefaction process, even higher at $130 \mathrm{CO}_{2}$-eq. $/ \mathrm{MJ}_{\mathrm{H}_{2}}$. Even if CCS is applied (on the gaseous chain) the emission factor amounts $35 \mathrm{CO}_{2 \text {-eq. }} / \mathrm{MJ}_{\mathrm{H}_{2}}$. Compared to the fossil gasoline emission factor of $12.5 \mathrm{CO}_{2 \text {-eq. }} / \mathrm{MJ}_{\text {fuel }}$ all hydrogen chains perform worse than the fossil Ref. [22]. Comparing the hydrogen storage technologies relative to each other, advanced storage technologies perform about $22 \%$ better on energy use than do conventional onboard storage technologies for the centralized chains and the gasoline reference chain. The least performing chains, using ICE non-hybrid drive train technology, perform poor on a (primary) mega joule per kilometre basis. Especially the chains using liquefied hydrogen use more than double the primary energy per kilometre than the reference chains. The advanced onboard storage technologies perform best, in the case of centralized hydrogen production even slightly better than the fossil and bio-based reference chains. An obvious advantage of hydrogen use as an energy carrier in transportation applications is the possibility of $\mathrm{CO}_{2}$ capture at production. Although an energy penalty has to be paid for $\mathrm{CO}_{2}$ capture, it can play a key role in mitigating transport related emissions, because over $85 \%$ of the emitted carbon dioxide can be captured [30].

Centralized produced hydrogen delivered to the fuelling station, with an average delivered energy use of $13.4 € / \mathrm{GJ}$, outperforms on-site production with an average of $27.7 € /$ GJ. Of the total cost, hydrogen production and liquefaction are by far the decisive cost factors. Hydrogen transportation, either in liquefied form by truck or gaseous by pipeline, only marginally contribute to the overall cost (Table 3). Indeed production, and when applicable, liquefaction account for more than half of the total cost on a $€ / G J$ basis. In all but the centralized produced and pipeline distributed chains, the production and liquefaction account for more than $80 \%$ of the total hydrogen cost. In production and delivery this puts the focus on production rather than deliverance to improve cost performance. For the total driving cost, three other aspects are included in the analysis; car expenditure, operation \& maintenance and, the focus of the paper, the storage tank cost. In the fossil and bio-based references cases car expenditure and O\&M account for the bulk of the driving cost, with $16 € \mathrm{c} / \mathrm{km}$ for gasoline and $18 € \mathrm{c} / \mathrm{km}$ for diesel over $80 \%$ of the total cost per kilometre. For the assessed hydrogen chains car expenditure and O\&M costs are higher compared to conventional ICEVS, because a higher cost for HFVs using PEM FC. Car expenditure for PEM FCVs is $25 \mathrm{\epsilon c} / \mathrm{km}$ with O\&M expenses of $10 \%$ of the capital expenditure per year. Also the fuel production and deliverance of hydrogen is slightly higher than for the reference cases in the total driving cost. The production and deliverance, however, do not, with $2 \mathrm{\epsilon c}_{\mathrm{c}} / \mathrm{km}$, account for more than $10 \%$ of the total driving cost and in the most costly hydrogen chain do not account for more than 3\%. The two advanced onboard storage technologies cost, contribute heavily to the total driving cost with $8.7 € \mathrm{c} / \mathrm{km}$ for $\mathrm{MH}$ and $14.4 \mathrm{€c} / \mathrm{km}$ for CNTs. The traditional hydrogen storage options, liquid and pressurized, contribute marginally to the total driving cost, with only $1 € \mathrm{c} / \mathrm{km}$ for gaseous and $2.3 € \mathrm{c} / \mathrm{km}$ for liquid storage. From this we conclude that at this stage advanced storage options lack the economic perspective, 
to develop into a competitive alternative to either the traditional hydrogen storage options or to the reference cases. The car expenditure and the O\&M cost contribute to the total driving cost heavily, especially for PEM fuel cell driven vehicles. The advanced storage cost add a significant additional cost that, when compared to the total reference cost, can at present be a showstopper. For the future it clearly emphasizes the importance of reducing cost of HFVs and advanced storage technology cost in order to make them a competitive alternative.

\section{References}

[1] McDowall W, Eames M. Forecasts, scenarios, visions, backcasts and roadmaps to the hydrogen economy: a review of the hydrogen futures literature. Energy Policy 2006;34:1236-50.

[2] Weiss MA, et al. On the road in 2020: a life-cycle analysis of new automobile technologies. Energy laboratory report MIT EL 00-003, Massachusetts Institute of Technology (MIT); 2000.

[3] Zaluska A, Zaluski L. Structure, catalysis and atomic reactions on the nano-scale: a systematic approach to metal hydrides for hydrogen storage. Appl Phys 2000;A(72):157-65.

[4] Shiraishi M, Takenobu T. et al. Hydrogen storage in single-walled carbon nanotube bundles and peapods. Chem Phys Lett 2002;358(3-4):213-8.

[5] Hirscher M, Becher M. Hydrogen storage in sonicated carbon materials. Appl Phys 2001;A(72):129-32.

[6] Dillon AC, Heben MJ. Hydrogen storage using carbon adsorbents: past, present and future. Appl Phys 2001;A(72):133-42.

[7] Ogden JA, Steinbugler MM. A comparison of hydrogen, methanol and gasoline as fuels for fuel cell vehicles: implications for vehicle design and infrastructure development. J Power Sources 1999;79:143-68.

[8] Simbeck D, Chang E. Hydrogen supply: cost estimate for hydrogen pathways—scoping analysis. National Renewable Energy Laboratory; 2002.

[9] Amos WA. Costs of storing and transporting hydrogen. National Renewable Energy Laboratory; 1998.

[10] James BD, et al. Comparison of onboard hydrogen storage for fuel cell vehicles. Prepared for Ford motor company under PRIME contract DEAC02-94CE50389 direct hydrogen-fueled proton-exchange-membrane (PEM) fuel cell system for transportation applications to the US Department of Energy; 1996.

[11] Intergovernmental Panel on Climate Change (IPCC)? 2005 (December 2005), 〈http://www.umich.edu/pres/committees/envrpt/etf_indicators. $\mathrm{html}\rangle$.

[12] Pehr K, Sauermann P, Traeger O, Bracha M. Liquid hydrogen for motor vehicles-the world's first public $\mathrm{LH}_{2}$ filling station. Int $\mathrm{J}$ Hydrogen Energy 2001;26:777-82.

[13] US Department of Energy (DOE). The hydrogen economy: opportunities, costs, barriers and R\&D needs. National Research Council and National Academy of Engineering of the National Academies; 2004.

[14] Bossel U, Eliasson B, Taylor G. The future of the hydrogen economy: bright or bleak. Updated version 15 April 2005; 2005.

[15] Yang RT. Hydrogen storage by alkali-doped carbon nanotubes—revisited. Carbon 2000;4:623-6.
[16] HERA Hydrogen Storage Systems Inc., 2005 (3 February), 〈http:// www.herahydrogen.com $\rangle$.

[17] Schlapbach L. Hydrogen storage. EMPA Materials Science and Technology Institution of the eth Domain and University of Fribourg, risø energy report 3.

[18] Dornheim M, Klassen T, Bormann R. Hydrogen storage materials. Technical University Hamburg, Hamburg, Germany; 2004.

[19] Neelis ML, van der Kooi HJ, Geerlings JJC. Exergetic life cycle analysis of hydrogen production and storage systems for automotive applications. Int J Hydrogen Energy 2004;29:537-45.

[20] Sherif SA, Zeytinoglu N, Veziroglu TN. Liquid hydrogen: potential, problems, and a proposed research program. Int J Hydrogen Energy 1997;22(7):683-8.

[21] Wang Q, Johnson JK. Optimization of carbon nanotubes for hydrogen adsorption. J Phys Chem B 1999;103(23):4809-13.

[22] European Commission (EU). Well-to-wheels analysis of future automotive fuels and powertrains in the European context, joint report of the European Commission Joint Research Centre, CONCAWE (the oil companies' European Association for Environment, Health and Safety in Refining and Distribution) and the EUCAR (European Council for Automotive R\&D); 2003.

[23] SAFE. 2005 (September), Website, at 〈http://www.safe-ita.com//.

[24] Ogden JM, et al. Hydrogen energy system studies. DOE report, contract no. XR-11265-2; 1995.

[25] European Commission (EC). European energy and transport-trends to 2030, office for official publications of the European communities; 2003.

[26] Castello P, Tzimas E, Moretto P, Peteves SD. Techno-economic assessment of hydrogen transmission \& distribution systems in Europe in the medium and long term. European Commission, Directorate General Joint Research Centre (DG JRC), The Institute for Energy, Petten, the Netherlands; 2005.

[27] Lelieveld J, Lechtenböhmer S, Assonov SS, Brenninkmeijer CAM, Dienst C, Fischedick M. et al. Greenhouse gases: low methane leakage from gas pipelines. Nature 2005;434:841-2.

[28] Sjardin M, Damen KJ, Faaij APC. Techno-economic prospects of smallscale membrane reactors in a future hydrogen-fuelled transportation sector. Energy 2004;31:2523-55.

[29] ChevronTexaco. 2005, An approach to distributed hydrogen production, 22 April 2005, 〈http://www.greencarcongress.com/2005/04/chevron texaco_a.html .

[30] Damen K, van Troost M, Faaij A, Turkenburg W. A comparison of electricity and hydrogen production systems with $\mathrm{CO}_{2}$ capture and storage. Part A: review and selection of promising conversion and capture technologies. Progr Energy Combust Sci 2006;32:215-46.

[31] International Panel on Climate Change (IPCC). Climate change 2001. Mitigation. Cambridge: Cambridge University Press; 2001.

[32] Parker N. Using natural gas transmission pipeline costs to estimate hydrogen pipeline costs. Institute of Transportation Studies, University of California; 2003.

[33] Hamelinck CN. Outlook for advanced biofuels. PhD thesis, Copernicus Institute, Utrecht University, Utrecht, The Netherlands; 2004.

[34] Allison JE, Cole GS. Metal-matrix composites in the automotive industry: opportunities and challenges; 1993.

[35] European Commission, Council Directive of 20 March 1970 on the approximation of the laws of the member states on measures to be taken against air pollution by emissions from motor vehicles. 